\title{
Space charge and steady state current in LDPE samples containing a permittivity/conductivity gradient
}

\author{
Holbøll, Joachim; Bambery, K. R.; Fleming, R. J.
}

Published in:

Conference on Electrical Insulation and Dielectric Phenomena

Link to article, DOI:

10.1109/CEIDP.2000.885305

Publication date:

2000

Document Version

Publisher's PDF, also known as Version of record

Link back to DTU Orbit

Citation (APA):

Holbøll, J., Bambery, K. R., \& Fleming, R. J. (2000). Space charge and steady state current in LDPE samples containing a permittivity/conductivity gradient. In Conference on Electrical Insulation and Dielectric Phenomena IEEE. https://doi.org/10.1109/CEIDP.2000.885305

\section{General rights}

Copyright and moral rights for the publications made accessible in the public portal are retained by the authors and/or other copyright owners and it is a condition of accessing publications that users recognise and abide by the legal requirements associated with these rights.

- Users may download and print one copy of any publication from the public portal for the purpose of private study or research.

- You may not further distribute the material or use it for any profit-making activity or commercial gain

- You may freely distribute the URL identifying the publication in the public portal 
2000 Conference on Electrical Insulation and Dielectric Phenomena

\title{
Space charge and steady state current in LDPE samples containing a permittivity/conductivity gradient
}

\author{
J.T. Holbøll, Dept. of Electric Power Engineering, Technical University of Denmark, DK-2800 Lyngby, \\ DENMARK
}

K.R. Bambery and R.J. Fleming, Dept. of Physics, Monash University, Melbourne, AUSTRALIA

\begin{abstract}
Electromagnetic theory predicts that a dielectric sample in which a steady dc current of density $j$ is flowing, and in which the ratio of permittivity $\varepsilon$ to conductivity $\sigma$ varies with position, will acquire a space charge density $\mathrm{j} \cdot \operatorname{grad}(\varepsilon / \sigma)$. A simple and convenient way to generate an $\varepsilon / \sigma$ gradient in a homogeneous sample is to establish a temperature gradient across it. The resulting spatial variation in $\varepsilon$ is usually small in polymeric insulators, but the variation in $\sigma$ can be appreciable. Laser induced pressure pulse (LIPP) measurements were made on 1.5 mm thick plaques of ultra pure LDPE equipped with vacuum-evaporated aluminium electrodes. Temperature differences up to $27^{\circ} \mathrm{C}$ were maintained across the samples, which were subjected to DC fields up to 20 $\mathrm{kV} / \mathrm{mm}$. Current density was measured as a function of temperature and field. Negligible thermally generated space charge was observed. The charge carrier mobility in the bulk of the samples was estimated to be of order $10^{-8} \mathrm{~cm}^{2} \mathrm{~V}^{-1} \mathrm{~s}^{-1}$.
\end{abstract}

\section{Introduction}

In power cables a thermal gradient normally exists across the insulation because of Joule heating in the central conductor and cooling by the surrounding ground. The resulting conductivity gradient is expected to generate space charge throughout the insulation volume. Several authors $[1,2,3]$, have emphasised that modern space charge measurement techniques are sufficiently sensitive to detect this thermally generated space charge.

In this paper we report LIPP measurements of space charge in polymeric samples across which a temperature gradient was established. LIPP measurements were also made under isothermal conditions, and current density was recorded as a function of temperature and field. For simplicity, planar samples were employed. The expected thermally generated space charge density $\rho$, when a steady state current density $j$ is flowing through the sample, is given by

$$
\rho=\mathbf{j} \cdot \nabla\left(\frac{\varepsilon_{r} \varepsilon_{0}}{\sigma}\right)
$$

where $\varepsilon_{\mathrm{r}}$ is the relative permittivity, $\varepsilon_{0}$ is the permittivity of free space and $\sigma$ is the conductivity. Coelho [2] shows that $\varepsilon_{\mathrm{r}}$ is relatively insensitive to changes in $T$. Thus, in one dimension,

$$
\rho(x)=-\varepsilon_{\mathrm{r}} \varepsilon_{0} j \frac{1}{\sigma^{2}(x)} \frac{d \sigma(x)}{d x}
$$

This may be rewritten as

$$
\rho(x)=-\varepsilon_{\mathrm{r}} \varepsilon_{0} E(x) \frac{1}{\sigma(x)} \frac{d \sigma(x)}{d T(x)} \frac{d T(x)}{d x} .
$$

It is usually reported that the mean conductivity $\sigma(T)$ follows an Arrhenius relation

$$
\sigma(T)=\sigma_{0} \exp \left(\frac{-E_{a}}{\mathrm{k} T}\right)
$$

where $\sigma_{0}$ is a constant of the material, $\mathrm{k}$ is Boltzmann's constant, $E_{a}$ is an activation energy and $T$ is the temperature of an isothermal sample. $\sigma(T)$ is given by

$$
\sigma(T)=j(T) / E
$$

where $j(T)$ is the steady state current density and $E$ is the applied voltage divided by the sample thickness. Differentiation of ( 4 ) gives

$$
\frac{d \sigma(T)}{d T}=\frac{E_{a}}{\mathrm{k} T^{2}} \sigma(T)
$$

If we assume tentatively that

$$
\frac{1}{\sigma(x)} \frac{d \sigma(x)}{d T(x)} \approx \frac{1}{\sigma(T)} \frac{d \sigma(T)}{d T} .
$$

then ( 3 ) becomes

$$
\rho(x)=-\varepsilon_{\mathrm{r}} \varepsilon_{0} E(x) \frac{E_{a}}{\mathrm{k} T^{2}(x)} \frac{d T(x)}{d x} .
$$

Substituting appropriate experimental values (see below), i.e. $\varepsilon_{\mathrm{r}}=2.3, E(x)=20 \mathrm{kV} / \mathrm{mm}, E_{a}=1.1 \mathrm{eV}$, $T(x)=330 \mathrm{~K}$ and $d T(x) / d x=27^{\circ} \mathrm{C} / 1.5 \mathrm{~mm}$, gives $|\rho(x)| \approx 0.9 \mathrm{C} / \mathrm{m}^{3}$.

\section{Experimental}

The samples were $1.5 \mathrm{~mm}$ thick plates of high purity cable grade LDPE. Aluminium electrodes, $50 \mathrm{~nm}$ thick, 
were formed on both sides of the samples by vacuum evaporation.

A sample holder was constructed to allow independent control of the electrode temperatures. Measurements were performed at the largest electrode temperature difference achievable with the system, i.e. one electrode at $70^{\circ} \mathrm{C}$ and the other at $43^{\circ} \mathrm{C}$. The system could also maintain isothermal sample conditions at temperatures in the range $30-70^{\circ} \mathrm{C}$ to $1^{\circ} \mathrm{C}$ accuracy.

The samples were subjected to dc applied fields up to $20 \mathrm{kV} / \mathrm{mm}$. During poling the current was recorded with an electrometer. When it stabilized, LIPP measurements were made periodically until the space charge profile stabilized. All the data presented here were recorded in this steady state.

\section{Results}

\section{Current density in isothermal samples}

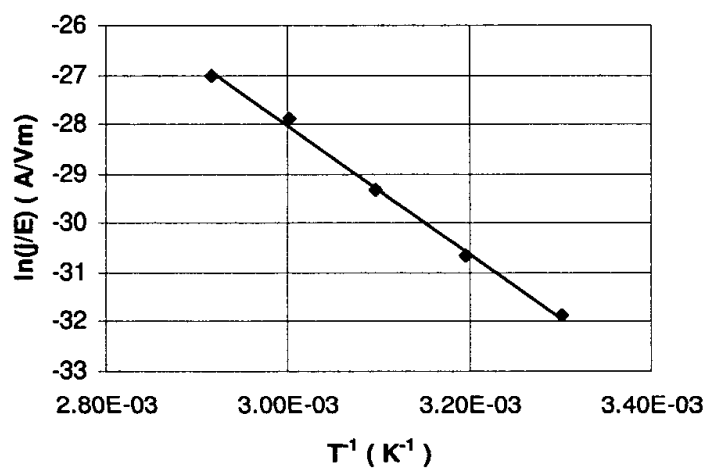

Fig. 1. Arrhenius plot of $\ln (\mathrm{j} / \mathrm{E})$ vs. 1/T for isothermal samples. Current densities were recorded at a field strength of $20 \mathrm{kV} / \mathrm{mm}$.

Figure 1 shows the measured temperature dependence of the conductivity for an isothermal sample. The calculated activation energy $E_{a}$ (eqn. ( 4 )) is $1.1 \pm 0.2$ $\mathrm{eV}$. The same value (within the quoted uncertainty) was obtained for all samples independent of the applied voltage polarity.

\section{Space charge density in isothermal samples}

Space charge profiles were obtained for isothermal samples following poling at $20 \mathrm{kV} / \mathrm{mm}$ and at temperatures of $30^{\circ} \mathrm{C}, 50^{\circ} \mathrm{C}$ and $70^{\circ} \mathrm{C}$.

Very little space charge was observed at 30 and $50^{\circ} \mathrm{C}$. The profile recorded at $70^{\circ} \mathrm{C}$ is shown in fig 2 . Measurable negative space charge accumulated adjacent to both electrodes, and positive space charge was just visible around the centre. This profile was very stable, changing very little when the sample stood for long periods at temperatures below $\sim 50^{\circ} \mathrm{C}$ with the electrodes grounded.

LIPP measurements were also performed on isothermal samples with the external field applied. Apart from the electrode charges the profiles were very similar to those recorded in short circuit.

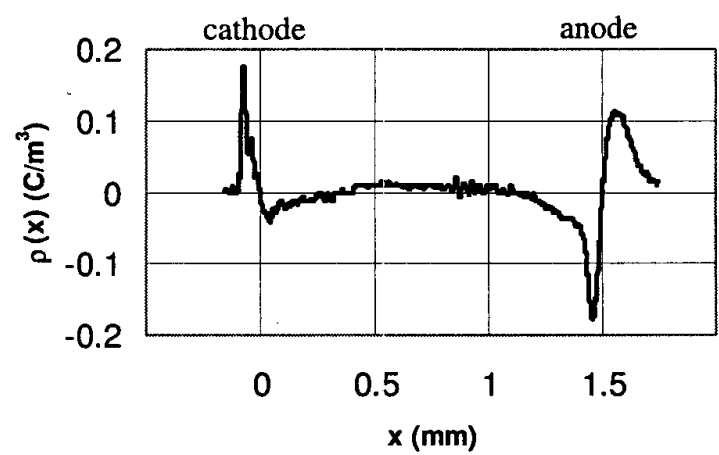

Fig. 2. Steady state space charge distribution obtained after poling an isothermal sample at $70^{\circ} \mathrm{C}$ and $20 \mathrm{kV} / \mathrm{mm}$. Electrodes were grounded during measurement.

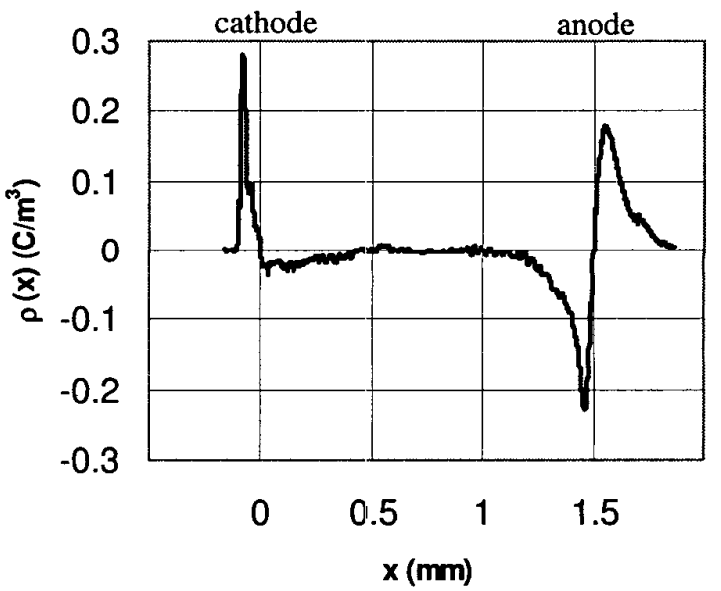

Fig. 3. Steady state space charge distribution obtained after poling but with a temperature gradient. The cathode and anode temperatures were $70^{\circ} \mathrm{C}$ and $43^{\circ} \mathrm{C}$ respectively. Electrodes were grounded during measurement.

\section{Space charge density in samples with a thermal gradient.}

Figure 3 shows the space charge profile for the same sample as in fig. 2 , but with the temperature gradient specified above established across it. Clearly the predicted uniform space charge density of $0.9 \mathrm{C} / \mathrm{m}^{3}$ was not observed.

The thermally generated space charge is expected to 
consist of "mobile" charge carriers, which could conceivably discharge rapidly to the electrodes when the electrodes were grounded. For this reason, LIPP measurements were repeated with the external field still applied (fig. 4). There is very little difference between figs. 3 and 4 in the bulk space charge at distances greater than the spatial resolution limit from the electrodes $(\sim 100 \mathrm{~nm})$.

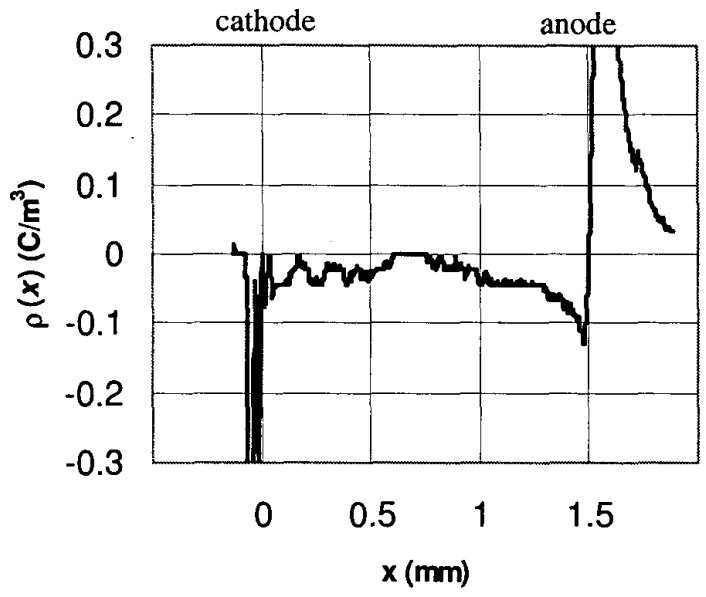

Fig. 4. Steady state space charge distribution under temperature gradient but with the field applied.

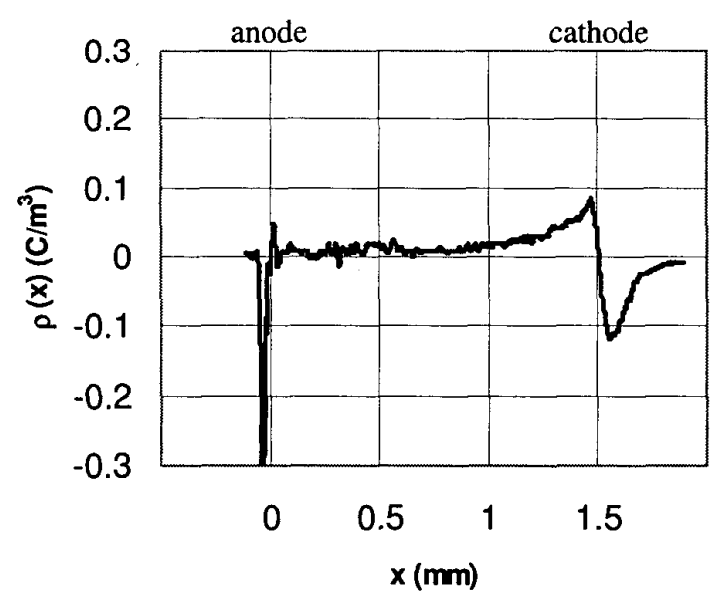

Fig. 5. Steady state space charge distribution under the fig. 3 conditions but with reversed field polarity. The anode and cathode temperatures were $70^{\circ} \mathrm{C}$ and $43^{\circ} \mathrm{C}$ respectively. Electrodes were grounded during measurement.

Figure 5 shows the space charge profile obtained for the same sample as in fig. 3 after poling under the same conditions but with reversed polarity. The considerable differences between these two figures, in the sample volume immediately adjacent to the electrodes, suggest considerable temperature sensitivity of the electron injection/extraction process at the electrodes, and/or inhomogeneity in the sample, i.e. the volumes immediately adjacent to the electrodes have different charge trapping characteristics.

Figure 6 shows the space charge profile obtained for the same sample as in fig. 3, after poling with the same polarity, but with the sample physically reversed. The differences (between these figures) in the volumes immediately adjacent to the electrodes again suggest different charge trapping characteristics. Further support for this suggestion is the observation that, when the isothermal sample was physically reversed, the negative charge density near the cathode increased while that near the anode decreased.

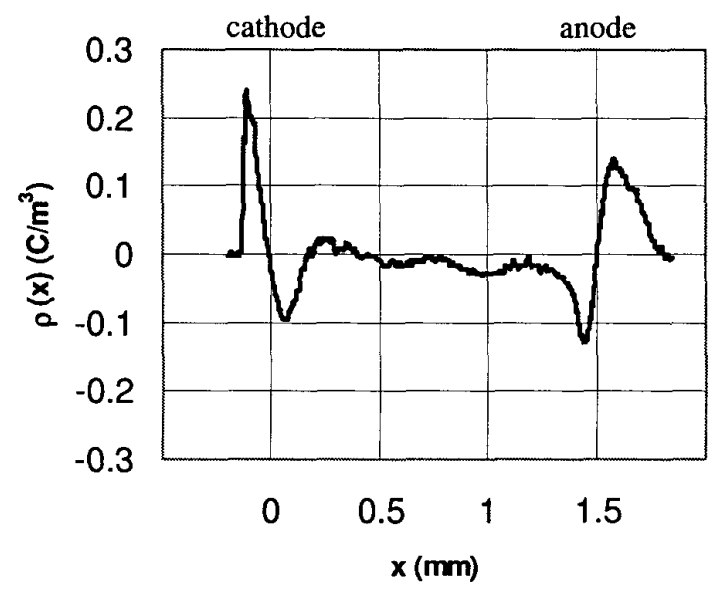

Fig. 6. Steady state space charge distribution obtained under the fig. 3 conditions, but with the sample reversed. The cathode and anode temperatures were $70^{\circ} \mathrm{C}$ and $43^{\circ} \mathrm{C}$ respectively. Electrodes were grounded during measurement.

\section{Discussion}

Since the samples were of high purity it is likely that any space charge observed was due principally to electrons and holes originally injected at the electrodes, rather than ions and electrons generated in the bulk via impurity ionization. Any contribution arising from a spatially inhomogeneous dipole concentration is also expected to be small.

\section{Isothermal samples}

The steady state current indicates that charge carriers were being transported across the sample. Hence we might expect to see additional bulk space charge (due to the presence of the charge carriers) in LIPP measurements made with the field applied. The expected thermally generated space charge would also consist of such mobile charge carriers. Since minimal space charge was observed in the bulk of isothermal samples, it is pertinent to consider whether LIPP can detect mobile charge carriers. Space does not permit a 
full discussion of this point here. Suffice to say that the important parameter is the effective mobilities of the charge carriers. It turns out that, in order that the carriers be detected in the present measurements, their mobilities must be less than approximately $10 \mathrm{~cm}^{2} / \mathrm{Vs}$. This condition is expected to be easily satisfied by almost all organic polymers.

We can estimate a lower limit to the carrier mobilities as follows. The mobile carrier charge densities must be less than or equal to the detection limit of the equipment, in this case $0.01 \mu \mathrm{C} / \mathrm{cm}^{3}$. A current density of $2.9 \times 10^{-11} \mathrm{~A} / \mathrm{cm}^{2}$ at $30^{\circ} \mathrm{C}$ and an applied field strength of $2 \times 10^{5} \mathrm{~V} / \mathrm{cm}$ then imply $\mu \geq 1.5 \times 10^{-8} \mathrm{~cm}^{2} / \mathrm{Vs}$. This figure is $1-3$ orders of magnitude larger than the lowest values previously reported for LDPE [4,5], but 4 orders of magnitude smaller than the highest reported values $[6,7]$.

\section{Samples with a temperature gradient}

The expected thermally generated space charge density around $0.9 \mathrm{C} / \mathrm{m}^{3}$ was not observed near the centre of the samples, nor indeed near the electrodes. [The space charge accumulating near the electrodes is mainly trapped charge injected from the electrodes, and is therefore of secondary interest here]. In figs. 3-6 very small differences in charge density can be seen around the centre of the samples, but they are at most $\pm 0.02 \mathrm{C} / \mathrm{m}^{3}$.

The most likely explanation for the discrepancy between the observed and calculated thermally generated space charge densities is that the assumption in eqn. (7) is incorrect, i.e. it now appears that the fractional variation with temperature of the conductivity in the bulk of a sample with a temperature gradient is much less than the fractional variation with temperature of the mean conductivity of an isothermal sample.

By analogy with eqn. (6) we may write

$$
\frac{1}{\sigma(x)} \frac{d \sigma(x)}{d T(x)}=\frac{E_{t r}}{\mathrm{k} T_{a \nu}{ }^{2}} .
$$

where $E_{t r}$ is the activation energy associated with the transport of mobile charge carriers through the bulk of a sample with average temperature $T_{a v}$. Replacing $E_{a} / \mathrm{k} T^{2}(x)$ in eqn. (8) by $E_{t r} / \mathrm{k} T_{a v}^{2}$, and assuming $\rho(x)=0.02 \mathrm{C} / \mathrm{m}^{3}$ (the maximum space charge density around the centre of the sample), gives $E_{t r} \approx 0.05 \mathrm{eV}$. This is much less than the activation energy $E_{a} \approx 1.1 \mathrm{eV}$ deduced from the temperature dependence of steady state currents (in isothermal samples) at constant applied field. Presumably $E_{a}$ is dominated by the energy required to inject an electron into the LDPE from the cathode. The present low value of $E_{t r}$ is similar to the activation energy of $0.1 \mathrm{eV}$ reported by Das Gupta and Noon [7] from phototransient spectral shifts in LDPE. It is interesting to note that these authors also found a relatively high charge carrier mobility $\left(\sim 1 \times 10^{-4}\right.$ $\mathrm{cm}^{2} / \mathrm{Vs}$ ).

The present data suggest a model of charge transport as follows:-

1) When the field is first applied, injected electrons (and holes) occupy traps near the electrodes.

2) Subsequently, injected charge carriers move between the electrodes with mobilities of order $10^{-8} \mathrm{~cm}^{2} / \mathrm{Vs}$, suffering very little deep trapping on the way.

\section{Conclusions}

The main findings for these planar high purity LDPE samples with aluminium electrodes were:-

a) In samples with a temperature gradient, negligible thermally generated space charge was observed, except immediately adjacent to the electrodes. Measurable space charge was detected there, but is thought to be due to trapping.

b) The fractional variation of the bulk conductivity with temperature, in a sample with a temperature gradient, was much less than the fractional variation of the mean conductivity with temperature in an isothermal sample.

c) The lower bound for charge carrier mobility in the bulk was approximately $1.5 \times 10^{-8} \mathrm{~cm}^{2} / \mathrm{Vs}$.

\section{Acknowledgments}

The authors thank Olex Cables Australia for the samples. RJF acknowledges receipt of an Australian Research Council grant.

\section{References}

1 I.W. McAllister, G.C. Crichton and A. Pedersen, "Charge accumulation in DC cables: A macroscopic approach", IEEE Intern. Symp. on Electr. Insul., Pittsbugh, pp. 212-216. 1994.

2 R. Coelho, "Charges in non homogeneous dielectrics", 1997 IEEE Annual Report - CEIDP, pp. 1-10. 1997.

3 B. Aladenize, R. Coelho, F. Guillaumond, P. Mirebeau, "On the intrinsic space charge in a DC power cable", J. of Electrostatics. 39. pp. 235-251. 1997.

4 H.J. Wintle, "Decay of static electrification by conduction processes in polyethylene", J. Appl. Phys. 41, 1970. p. 4004-4007.

$5 \mathrm{~T}$. Mizutani and M. Ieda, "Carrier transport in highdensity polyethelene", J. Phys. D: Appl. Phys. 12, pp. 291-296. 1979.

6 T. Tanaka and J.H. Calderwood, "Transient currents and electron mobility in polyethylene", J. Phys. D: Appl. Phys. 7, pp. 1295-1302. 1974.

7 D.K. Das Gupta and T. Noon, "Phototransient spectral shifts in polyethylene with high fields", J. Phys. D: Appl. Phys. 8, pp. 1333-1339. 1975. 